\title{
Study of the Dynamic Development Law of Overburden Breakage on Mining Faces
}

\author{
Hongqing Zhu ${ }^{1,2}$, Shuhao Fang $\mathbb{1}^{1,2^{*}}$, Yujia Huo ${ }^{1}$, Jinlin Guo ${ }^{1}$, Yan $\mathrm{Wu}^{1}$ \& Lintao Hu${ }^{1}$ \\ Based on the geological conditions of overburden rock, the dynamic development law of overburden \\ breakage was investigated by theoretical analysis and similarity model experiments in this paper. The \\ formula of the compressive strength and No. ratio was obtained by testing the compressive strength \\ of cylinder samples of similar materials. It can be seen from the overburden fracture evolution model \\ established by theoretical calculations and similarity model experiments that the overlying rock layer's \\ breakage law is consistent. Additionally, the height of the "three zones" and the law of the fracture \\ angle are basically consistent. Obtaining the synchronous collapse of the overlying strata controlled \\ by the key strata, the interval of the upper key strata is larger than that of the lower key strata, and \\ the mining interval is approximately double the size of the deformed rock height. According to the \\ overburden movement, the distribution law of the overburden separation rate is obtained. The strain in \\ the stress concentration area is negative, and when the stress is released suddenly, the strain increases \\ rapidly. Fracture development is detected by the $p$-wave velocity in the model. Moreover, certain \\ guidance for the horizon selection of high and low-level gas drainage roadways is provided by this \\ study.
}

Coal is asignificant source of energy ${ }^{1-3}$, but the production process is often disastrous. It is very important for the mining face pressure control and the horizon selection of high- and low-level drainage roadways to explore the dynamic development law of overlying strata breakage. According to the traditional "three zones" theory ${ }^{4-7}$, when the mining face moves forward, the roof strata will hang out and then fail, forming a caving zone, a fractured zone and a bending subsidence zone. The "three zones" have their own characteristics of rock strata movement and deformation.

Many research results on mine pressure and rock strata movement have been reported; among them, the key stratum theory is the mainstream theory at present ${ }^{8-13}$. He et al. ${ }^{14}$ analyzed the mechanisms of mining tremors caused by key strata movement and instability. Sun et al. ${ }^{15}$ proposed a similar hyperbolic settlement model to describe the movement and failure of internal loads. Fan and Liu ${ }^{16}$ proposed a conceptual model of broken rock mass compaction by elastic theory. Luan et al. ${ }^{17}$ determined that the thickness and span of key strata have a more dominant effect on the stability of key strata compared with other factors, and the increase in uncertainty levels leads toa decrease in the stability probability. Liang et al. ${ }^{18}$ showed that in a fully mechanized mining face with a high mining height, the first subordinate key layer has two structural forms and six types of movement. Xie and $\mathrm{Xu}^{19}$ researched the key stratum effect on the mining abutment pressure of a coal seam. Han $e$ t al. ${ }^{20}$ presenteda method to calculate the working surface abutment pressure by key strata theory. Gao et al. ${ }^{21}$ demonstrated that the first fracture occurrence ofthe key layer increases the displacement and the stress and that the second fracture partially releases the stress.

Similarity model experiments are common methods for studying overburden. In recent years, much research has been done on the two-zone failure mode and related cracks in overlying strata on the working face of shallow thick seams $s^{22-26}$. Liet al. ${ }^{27}$ studied the impact of the compound breakage of key strata on the overburden movement and strata pressure behavior during fully mechanized caving mining in shallow and extremely thick seams based onUDEC numerical simulation software. Kang et al. ${ }^{28}$ created a large-scale similarity model experimentsusing a real case to simulate massive roof collapse during longwall coal retreating mining. Le et al. ${ }^{29}$ proposed a discontinuous modeling method to research longwall top coal caving behavior, including the stress distribution,

${ }^{1}$ School of Emergency Management and Safety Engineering, China University of Mining and Technology (Beijing), Beijing, China. ${ }^{2}$ State Key Laboratory Coal Resources and Safe Mining, China University of Mining and Technology (Beijing), Beijing, China. *email: 13051880533@163.com 
coal and rock failures, top coal caving and roof strata rupture, and to analyze the impact of overlying strata movement on top coal caving. The similarity model experiments was used to calculate the formation and distribution of overlying stratacracksinduced by uplift mining ${ }^{30}$. Using the similarity model experiments, the movement laws of the overlying strata in the upper and lower strata were analyzed ${ }^{31}$. The development height of an air-conducting fracture zone in the gob overburdenwas verifiedthrougha similarity model experiments and numerical simulation of particle flow code software ${ }^{32}$. By means of a theoretical analysis and physical and numerical simulations, He et al. ${ }^{33}$ analyzed the motion boundary shapes of bedrock and unconsolidated formations, establishedthe motion boundary fitting equations for both, analyzed the influence of key formations on the formation motion boundary shapes, and determined the principle of setting protective coal pillars. The failure law of overlying strata and the development of the "three belts" were studied through similarity model experiments, and the failure mode and rock failure under the weak cement roof mining conditions of longwall top coal mining were analyzed ${ }^{34}$. Ju and $\mathrm{Xu}^{35}$ determined and defined three structural models via field observations, similarity model experiments and theoretical analyses of the first longwall face with a $7.0 \mathrm{~m}$ mining height; these modelswere affected by the relative position of key stratain the overlying strata. Zhou et al..$^{36}$ used theoretical analysis and similarity model experiments methods and found that the fracture has two development cycles and two peaks. In the three-dimensional similarity model experiments, the deformation law of overburden caused by continuous coal seam mining was studied $^{37}$. Yan et al. ${ }^{38}$ investigatedthe shaft deformation law under caving and backfill mining bythe similarity criteria of similarity model experiments. The stability evolution law of clay aquifers during mining of extremely thick coal seams was studied through similarity model experiments ${ }^{39}$. Ghabraie et al. ${ }^{40}$ investigated the characteristics of multi-seam subsidence by means of several sand-plaster physical models.

Similarity model experiments are commonly used to study overlying rocks. Previous studies mostly used a comparative analysis of similar experimental results with UDEC or FLAC3d simulation results, mostly analyzing fracture zones. Similar experimental models stratified less. In addition, there have been few experimental tests of similar materials in the literature; that is, cylinder sample experiments and little support for overburden breaking models based on theoretical calculations have been found. The analysis of collapse zones and analysis from each layer of the seam roof have rarely been seen. In this paper, the following objectives are presented: (1)Cylinder sample experiments are performed to provide a basis for the selection of similar materials. (2)Based on the on-site geological conditions, the overburden fracture evolution model ofthe mining face is established according to the calculation method of key strata theory, the fracture angle of layer theory and "three zones" theory. (3)The overburden breaking model established based on theoretical calculations verifies the accuracy of the similarity model experiments, determines the key strata level of overburden on the working face of deep thick seams, and obtains the distribution law and the breaking angle of the overlying strata. Additionally, the height of the caving zone and the fractured zone, the strain change law and the damage degree of the overburden are obtained.

It is necessary to arrange 3 roadways for the mining of the working face in a mine in Shanxi Province to solve the problem of gas drainage, which leads to complicated construction management conditions, a large amount of engineering work and an extremely difficult connection between mining and tunneling. A new method of highand low-level gas drainage roadways is proposed to solve the problem of gas drainage. The method mentioned in this paper has certain guidance for the working face pressure control and the horizon selection of high- and low-level gas drainage roadways.

\section{Cylinder sample uniaxial compression test}

The average thickness of the main mining $15 \#$ coal seam is $5.4 \mathrm{~m}$, the average dip angle is $4^{\circ}$, and the average buried depth is $480 \mathrm{~m}$. The daily mining distance of this working face is $6.4 \mathrm{~m}$. There are two surface boreholes in the mining face, and the lithology and thickness of overburden rock on the mining face can be obtained by the comprehensive bar chart of the mine. The overburden rock parameters of the mining face are shown in Table 1.

Experimental design. To obtain the right ratio of similar materials depending on the compressive strength of similar materials, a cylinder sample (i.e., $50 \mathrm{~mm}$ in diameter, $100 \mathrm{~mm}$ high) with sand, lime, gypsum and water was made. The No. ratio of the material is $A B(10-B)$; the quality proportions of sand, lime and gypsum are $A /$ $(A+1), B /[10(A+1)]$ and $(10-B) /[10(A+1)]$, respectively.

To optimize the number of cylinder samples, an orthogonal experiment was designed, taking the proportion of sand as the level and sand, lime and gypsum as the factors. The orthogonal design is shown in Table 2.

The volume of the cylinder sample is $196.35 \mathrm{~cm}^{3}$, and the mass is $314.16 \mathrm{~g}$, according to the apparent density of $1.6 \mathrm{~g} / \mathrm{cm}^{3}$. The water mass is $34.91 \mathrm{~g}$ according to $1 / 9$ th of the cylinder sample mass. The components were calculated according to the No. ratio, as shown in Table 3. The cylinder sample model is shown in Fig. 1.

Experimental results. A uniaxial compression test was conducted with a universal servo testing machine to test the compressive strength of the cylinder sample. The experimental process is shown in Fig. 2. The compressive strength obtained from the test is shown in Table 3.

The sum of the No. ratios of lime and gypsum is 10 . The compressive strength of the cylinder sample is a function of the No. ratio of sand and lime, where the No. ratios of sand and lime are independent variables, and their relation is shown in Fig. 3.

The compressive strength of the cylinder sample decreases with an increasing No. ratio of sand and lime. With an increase in the No. ratio of sand, the influence of the No. ratio of lime on the compressive strength of the cylinder sample decreases. In parallel, with an increase in the No. ratio of lime, the influence of the No. ratio of sand on the compressive strength of the cylinder sample decreases. The No. ratio of sand and lime are independent variables $x$ and $y$, respectively, and compressive strength is the dependent variable $f(x, y)$. Using MATLAB to select the polynomial fit for the fitting, the fitting formula is shown as Eq. (1), and the fitting diagram is shown in Fig. 4. 


\begin{tabular}{|c|c|c|c|c|c|c|c|c|c|c|}
\hline No. & Lithology & $H_{i} / \mathrm{m}$ & $h_{i} / \mathrm{m}$ & $P_{a i} / \mathrm{MPa}$ & $P_{b i} / \mathrm{MPa}$ & No. ratio & $\gamma_{i} /\left(\mathrm{KN} / \mathrm{m}^{3}\right)$ & $E_{i} / \mathrm{GPa}$ & $R_{i} / \mathrm{MPa}$ & $\varphi_{i} /^{\circ}$ \\
\hline 38 & Sandy mudstone & 280 & 10 & 50 & 0.16 & 537 & 25 & 15 & 10 & \\
\hline 37 & gritstone & 270 & 6 & 120 & 0.38 & 337 & 25.3 & 28 & 12 & \\
\hline 36 & Siltstone & 264 & 8 & 90 & 0.28 & 355 & 26 & 18 & 7 & \\
\hline 35 & Sandy mudstone & 254 & 6 & 52 & 0.16 & 537 & 25 & 15 & 10 & \\
\hline 34 & mid-stone & 248 & 12 & 130 & 0.41 & 328 & 25.5 & 25 & 11 & \\
\hline 33 & Sandy mudstone & 236 & 16 & 40 & 0.13 & 719 & 25 & 15 & 10 & \\
\hline 32 & Siltstone & 220 & 12 & 90 & 0.28 & 355 & 26 & 18 & 7 & \\
\hline 31 & mid-stone & 208 & 4 & 130 & 0.41 & 328 & 25.5 & 25 & 11 & \\
\hline 30 & Sandy mudstone & 204 & 6 & 40 & 0.13 & 719 & 25 & 15 & 10 & \\
\hline 29 & Siltstone & 198 & 6 & 90 & 0.28 & 355 & 26 & 18 & 7 & \\
\hline 28 & mid-stone & 192 & 16 & 130 & 0.41 & 328 & 25.5 & 25 & 10 & \\
\hline 27 & Siltstone & 176 & 8 & 90 & 0.28 & 355 & 26 & 18 & 7 & \\
\hline 26 & Sandy mudstone & 168 & 6 & 40 & 0.13 & 719 & 25 & 15 & 10 & \\
\hline 25 & Fine sandstone & 162 & 8 & 110 & 0.34 & 337 & 25.5 & 23 & 11 & \\
\hline 24 & Sandy mudstone & 154 & 10 & 40 & 0.13 & 719 & 25 & 15 & 10 & \\
\hline 23 & mid-stone & 144 & 8 & 120 & 0.38 & 337 & 25.5 & 25 & 10 & \\
\hline 22 & Sandy mudstone & 136 & 10 & 40 & 0.13 & 719 & 25 & 16 & 11 & \\
\hline 21 & No. $8_{1}$ coal & 126 & 1 & 10 & 0.03 & 1182 & 14 & 0.3 & 0.1 & \\
\hline 20 & Mudstone & 125 & 3 & 40 & 0.13 & 719 & 24 & 10 & 1 & \\
\hline 19 & Siltstone & 122 & 8 & 65 & 0.20 & 519 & 26 & 18 & 7 & \\
\hline 18 & No. $8_{4}$ coal & 114 & 1 & 10 & 0.03 & 1182 & 14 & 0.3 & 0.1 & \\
\hline 17 & Sandy mudstone & 113 & 4 & 40 & 0.13 & 719 & 25 & 15 & 10 & \\
\hline 16 & Fine sandstone & 109 & 4 & 110 & 0.34 & 337 & 26 & 20 & 10 & \\
\hline 15 & No. 9 coal & 105 & 1 & 10 & 0.03 & 1182 & 14 & 0.3 & 0.1 & \\
\hline 14 & Sandy mudstone & 104 & 4 & 30 & 0.09 & 755 & 25 & 15 & 3 & \\
\hline 13 & Fine sandstone & 100 & 14 & 100 & 0.30 & 346 & 25.3 & 28 & 11 & \\
\hline 12 & K4 Limestone & 86 & 2 & 120 & 0.38 & 337 & 26 & 40 & 18 & \\
\hline 11 & Sandy mudstone & 84 & 6 & 30 & 0.09 & 755 & 25 & 15 & 3 & \\
\hline 10 & gritstone & 78 & 4 & 80 & 0.25 & 355 & 25.3 & 28 & 12 & \\
\hline 9 & mid-stone & 74 & 12 & 75 & 0.23 & 437 & 25.5 & 25 & 11 & 43 \\
\hline 8 & Sandy mudstone & 62 & 4 & 30 & 0.09 & 873 & 25 & 15 & 3 & 38 \\
\hline 7 & K3 Limestone & 58 & 4 & 120 & 0.38 & 337 & 26 & 40 & 18 & 45 \\
\hline 6 & Fine sandstone & 54 & 5 & 65 & 0.20 & 519 & 26 & 20 & 10 & 42 \\
\hline 5 & Sandy mudstone & 49 & 8 & 20 & 0.06 & 773 & 25 & 15 & 3 & 38 \\
\hline 4 & K2 Limestone & 41 & 5 & 120 & 0.38 & 337 & 26 & 40 & 18 & 45 \\
\hline 3 & Sandy mudstone & 36 & 6 & 20 & 0.06 & 773 & 25 & 15 & 3 & 38 \\
\hline 2 & Fine sandstone & 30 & 8 & 65 & 0.20 & 519 & 26 & 20 & 10 & 42 \\
\hline 1 & Sandy mudstone & 22 & 4 & 20 & 0.06 & 773 & 25 & 15 & 3 & 38 \\
\hline 0 & No. 15 coal & 18 & 5.4 & 10 & 0.03 & 1182 & 14 & 0.3 & 0.1 & - \\
\hline-1 & Sandy mudstone & 12.6 & 12.6 & 60 & 0.19 & 528 & 25 & 15 & 3 & - \\
\hline
\end{tabular}

Table 1. Overburden parameters. Note: $H_{i}$-total thickness at the i-th layer; $h_{i}$-thickness of layer $i ; P_{a i}-$ prototype compressive strength of layer $i ; P_{b i}$-model compressive strength of layer $i ; \gamma_{i}$-body force of layer $i$; $E_{i}$ - elastic modulus of layer $i ; R_{i}$-tensile strength of layer $i ; \varphi_{i}$-friction angle of layer $i$.

\begin{tabular}{|l|l|l|l|l|}
\hline Level & $\mathbf{1}$ & $\mathbf{2}$ & $\mathbf{3}$ & $\mathbf{4}$ \\
\hline Sand: Gels & $3: 1$ & $5: 1$ & $7: 1$ & $9: 1$ \\
\hline Lime: Gypsum & $1: 9$ & $3: 7$ & $5: 5$ & $7: 3$ \\
\hline
\end{tabular}

Table 2. Ratio level.

$$
\begin{aligned}
f(x, y)= & 1.928-0.7326 x-0.1455 y+0.1013 x^{2}+0.0412 x y \\
& -0.004708 x^{3}-0.003163 x^{2} y \quad \mathrm{R}^{2}=0.9924
\end{aligned}
$$

In Eq. (1), $x$ is an integer ranging from 3 9, and $y$ is an integer ranging from 1 9, from which the No. ratio of the desired compressive strength can be obtained, and the No. ratio of similar materials corresponding to the compressive strength of rocks can be obtained according to the similarity ratio, as shown in Table 1.The parameters used in the following are listed in Table 1. 


\begin{tabular}{|l|l|l|l|l|l|}
\hline $\begin{array}{l}\text { No. } \\
\text { experimental }\end{array}$ & $\begin{array}{l}\text { No. } \\
\text { ratio }\end{array}$ & $\begin{array}{l}\text { Mass of } \\
\text { sand/g }\end{array}$ & $\begin{array}{l}\text { Mass of } \\
\text { lime/g }\end{array}$ & $\begin{array}{l}\text { Mass of } \\
\text { gypsum/g }\end{array}$ & $\begin{array}{l}\text { Compressive } \\
\text { strength/MPa }\end{array}$ \\
\hline 1 & 319 & 235.62 & 7.854 & 70.686 & 0.473 \\
\hline 2 & 337 & 235.62 & 23.562 & 54.978 & 0.368 \\
\hline 3 & 355 & 235.62 & 39.27 & 39.27 & 0.251 \\
\hline 4 & 373 & 235.62 & 54.978 & 23.562 & 0.14 \\
\hline 5 & 391 & 235.62 & 70.686 & 7.854 & 0.083 \\
\hline 6 & 519 & 261.8 & 5.236 & 47.124 & 0.203 \\
\hline 7 & 537 & 261.8 & 15.708 & 36.652 & 0.144 \\
\hline 8 & 555 & 261.8 & 26.18 & 26.18 & 0.107 \\
\hline 9 & 573 & 261.8 & 36.652 & 15.708 & 0.074 \\
\hline 10 & 591 & 261.8 & 47.124 & 5.236 & 0.052 \\
\hline 11 & 719 & 274.89 & 3.927 & 35.343 & 0.137 \\
\hline 12 & 737 & 274.89 & 11.781 & 27.489 & 0.112 \\
\hline 13 & 755 & 274.89 & 19.635 & 19.635 & 0.087 \\
\hline 14 & 773 & 274.89 & 27.489 & 11.781 & 0.062 \\
\hline 15 & 791 & 274.89 & 35.343 & 3.927 & 0.041 \\
\hline 16 & 919 & 282.74 & 3.142 & 28.274 & 0.076 \\
\hline
\end{tabular}

Table 3. Compressive strength corresponding to the No. ratio.

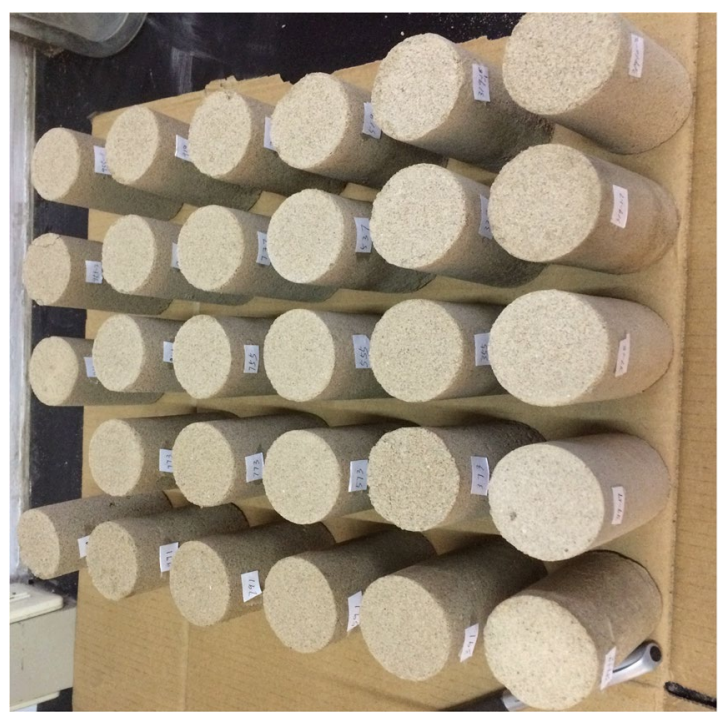

Figure 1. Cylinder sample model.
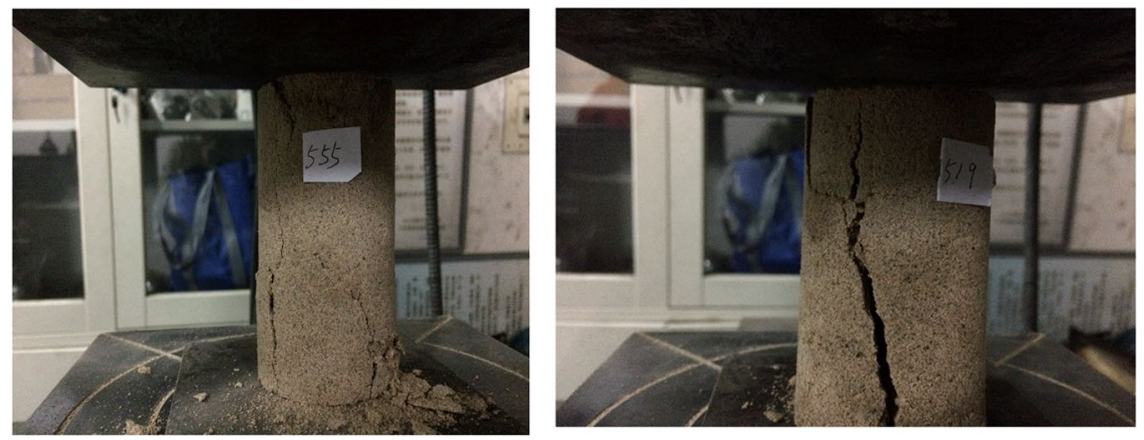

Figure 2. Cylinder sample fracturing process. 


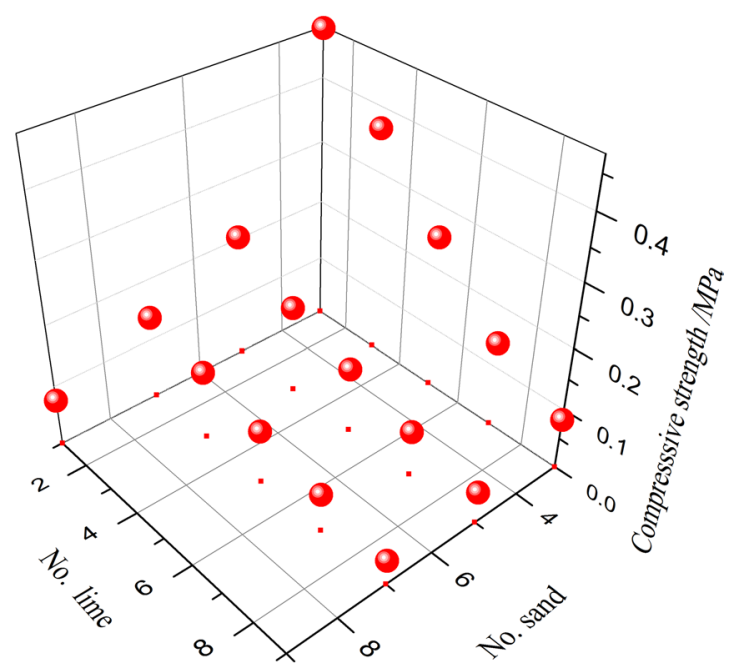

Figure 3. The relationship between the No. ratio and compressive strength.

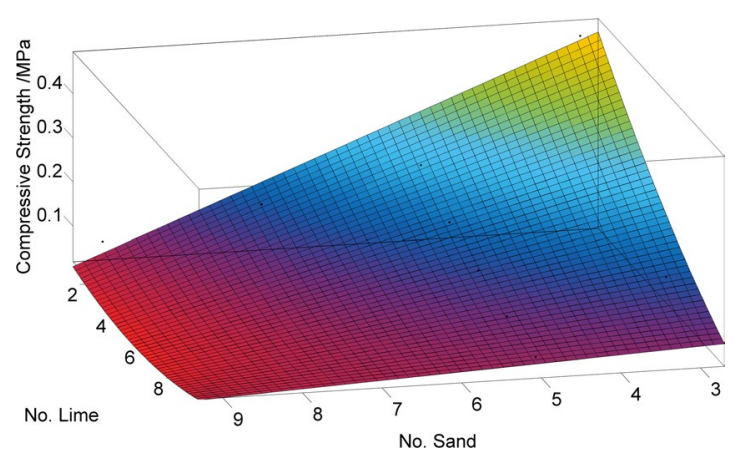

Figure 4. Fitting result.

\section{Overburden theoretical calculation model}

Calculation of the overburden "three zones". According to the theory of mine pressure control ${ }^{41,42}$, the maximum height of the caving zone of the general working face is calculated by formula (2) when the overburden is medium hard. In the hard overburden case, it can be calculated by formula (3):

$$
\begin{aligned}
& H_{c}=\frac{100 M}{4.7 M+19} \pm 2.2=9.97 \sim 14.37 \\
& H_{c}=\frac{100 M}{2.1 M+16} \pm 2.5=17.25 \sim 22.25
\end{aligned}
$$

Where $H c$ is the height of the caving zone, $\mathrm{m}$; and $M$ is the mining height of the coal seam, $5.4 \mathrm{~m}$.

The upper part of the coal seam is a thinner mudstone, the upper part of the mudstone is a thicker fine sandstone, and the upper part of the thicker fine sandstone is a hard limestone. The whole part is between medium hard and hardrock; therefore, the height of the caving zone is $14.37 \sim 17.25 \mathrm{~m}$.

The maximum height of the fractured zone is calculated by formula (4) when the overburden is hard: ${ }^{43}$

$$
H_{f}=\frac{100 M}{1.2 M+2} \pm 8.9=54.8 \sim 72.6
$$

Where $H_{f}$ is the height of the fractured zone, $\mathrm{m}$.

Because the overburden has more limestone and sandstone, the whole is hard rock, so the maximum height of the fractured zone is $54.8 \sim 72.6 \mathrm{~m}$.

Calculation of overburden breakage. According to the key stratum theory calculation formula ${ }^{44,45}$, the parameter to obtain the load $q_{1}$ of the first layer itself is:

$$
q_{1}=\gamma_{1} * h_{1}=25 * 4=100 \mathrm{KPa}
$$




\begin{tabular}{|l|l|l|l|l|l|}
\hline No. & $\left(\mathbf{L}_{\mathbf{a}}\right)_{\mathbf{i}} / \mathbf{m}$ & $\left(\mathbf{L}_{\mathbf{b}}\right)_{\mathbf{i}} / \mathbf{m}$ & $\left(\boldsymbol{\beta}_{\mathbf{a}}\right)_{\mathbf{i}} /^{\circ}$ & $\left(\boldsymbol{\beta}_{\mathbf{b}}\right)_{\mathbf{i}} \mathbf{l}^{\circ}$ & $\begin{array}{l}\text { Control } \\
\text { height } / \mathbf{m}\end{array}$ \\
\hline 1 & 31 & 12.6 & 69.4 & 68 & 4 \\
\hline 2 & 68.5 & 28.3 & 67.4 & 66.3 & 14 \\
\hline 4 & 71.2 & 29.1 & 66.8 & 65.9 & 28 \\
\hline 9 & 76.6 & 31.3 & 67.4 & 66.3 & 22 \\
\hline
\end{tabular}

Table 4. Roof breaking interval and the fracture angle of key stratum.

Considering the effect of the second layer on the first layer, the load on the first layer is:

$$
\left(q_{2}\right)_{1}=\frac{E_{1} * h_{1}^{3}\left(\gamma_{1} * h_{1}+\gamma_{2} * h_{2}\right)}{E_{1} * h_{1}^{3}+E_{2} * h_{2}^{3}}=26.4 \mathrm{KPa}
$$

Where $\left(q_{m}\right)_{n}$ represents the load on the $\mathrm{n}$ layer when the rock at the $\mathrm{m}$ layer above the $\mathrm{n}$ layer is calculated, KPa.

The effect of the second layer on the first layer should not be considered by reference to the key stratum theory, because the second layer is strong and thick and has no effect on the first layer, so the first layer is subjected to a load of $100 \mathrm{KPa}$.

Similarly, $q_{2}=208 \mathrm{KPa},\left(q_{2}\right)_{2}=272.8 \mathrm{KPa},\left(q_{3}\right)_{2}=271 \mathrm{KPa}$, the load on the second layer is $272.8 \mathrm{KPa}$, and the upper strata are controlled by it.

Similarly, $q_{4}=130 \mathrm{KPa},\left(q_{2}\right)_{4}=130.1 \mathrm{KPa},\left(q_{3}\right)_{4}=151.5 \mathrm{KPa},\left(q_{4}\right)_{4}=159 \mathrm{KPa},\left(q_{5}\right)_{4}=177.5 \mathrm{KPa},\left(q_{6}\right)_{4}=$ $78.4 \mathrm{KPa}$, the load on the fourth layer is $177.5 \mathrm{KPa}$, and the upper four strata are controlled by it.

Similarly, $q_{9}=306 \mathrm{KPa},\left(q_{2}\right)_{9}=391 \mathrm{KPa},\left(q_{3}\right)_{9}=499 \mathrm{KPa},\left(q_{4}\right)_{9}=540.3 \mathrm{KPa},\left(q_{5}\right)_{9}=315 \mathrm{KPa}$, so the loading on the ninth layer is $540.3 \mathrm{KPa}$, and the upper three layers are controlled by it.

Based on the theory of clamped-clamped beams in material mechanics ${ }^{45,46}$, when the maximum normal stress at both ends of the beam is equal to the tensile strength of rock, the overburden will be broken for the first time. The periodic interval of roof breaking is calculated by reference to the cantilever theory of material mechanics ${ }^{47}$. The first interval of roof breaking of layer $i$ is recorded as $\left(L_{a}\right)_{i}$, and the period is recorded as $\left(L_{b}\right)_{i}$. The formula is as follows:

$$
\begin{aligned}
& \left(L_{a}\right)_{i}=h_{i} * \sqrt{\frac{2 R_{i}}{q_{i}}} \\
& \left(L_{b}\right)_{i}=h_{i} * \sqrt{\frac{R_{i}}{3 q_{i}}}
\end{aligned}
$$

It is estimated that $\left(L_{b}\right)_{i}=\left(L_{a}\right)_{i} / 2.45$.

The mechanical derivation angle of the maximum principal stress and horizontal stress can be obtained as follows: $\theta_{1}=(1 / 2) \tan ^{-1}(3 L / h)$, where $L$ represents the suspended span length of the beam, $\mathrm{m}$, and $h$ represents the thickness of the key stratum, $m$.

The suspended span length of the rock beam is always larger than the height of the rock beam, and $3 \mathrm{~L} / \mathrm{h}$ is larger than 3 , thus $45^{\circ}>\theta_{1}>35^{\circ}$.

According to the Mohr-Coulomb criterion ${ }^{48,49}$, the angle between the rock damage plane and the maximum principal stress is $\theta_{2}=45^{\circ}-\varphi / 2$, where $\varphi$ represents the angle of the internal friction of the rock, ${ }^{\circ}$.

If the friction angle of sandstone and limestone is generally $20^{\circ} \sim 60^{\circ}$, then $35^{\circ}>\theta_{2}>15^{\circ}$.

The calculation formula of the included angle between the rock damage plane and the horizontal plane is as follows:

$$
\beta=45^{\circ}-\frac{\varphi}{2}+\frac{1}{2} \tan ^{-1} \frac{3 L}{h}
$$

Where $\beta$ is the fracture angle, ${ }^{\circ}$, and $80^{\circ}>\beta>50^{\circ}$. The first fracture angle of layer $i$ is recorded as $\left(\beta_{a}\right)_{i}$. The periodic fracture angle of layer $i$ is recorded as $\left(\beta_{b}\right)_{i}$.

Through the analysis of the formula of the roof breaking interval of rock, it can be concluded that the length and thickness of the rock beam and the rock shape have little influence on the rock fracture angle, which is only approximately $10^{\circ}$. In addition, the property of the rock friction angle has a great influence on the rock fracture angle.

According to the theoretical formula, the roof breaking interval and fracture angle of each stratum can be calculated, as shown in Table 4:

The periodic the roof breaking interval of key strata is less than the first roof breaking interval. According to the calculation formula of the fracture angle of key strata, the periodic fracture angle is less than the first fracture angle.

If the roof breaking interval of the lower strata whose is smaller than that of the upper strata, then the lower strata is the key strata, with reference to the key strata theory. Therefore, it can be determined that the first, second and fourth strata are the key strata. 


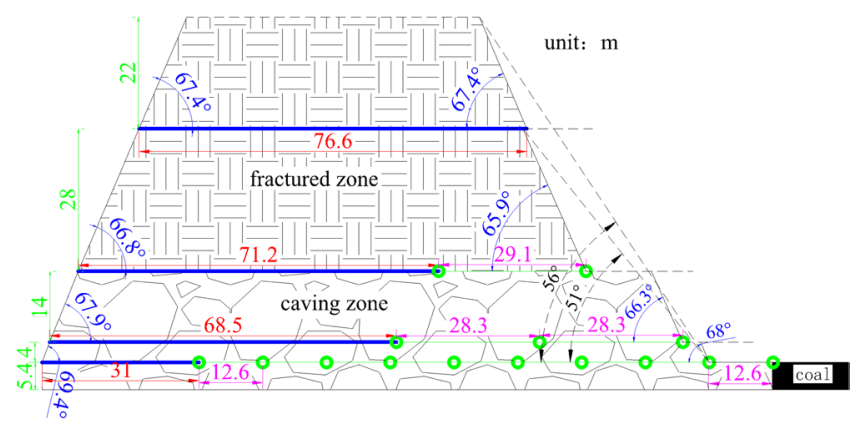

Figure 5. Overburden fracture evolution model.

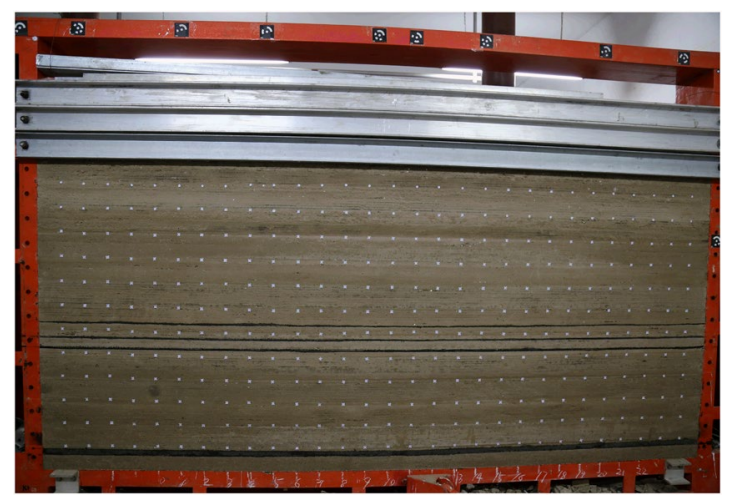

Figure 6. Experimental model.

According to the control height of the key strata and the theoretical calculation results of the "three zones" of overburden, the height of the caving zone is the control height of the second key strata $(18 \mathrm{~m})$, and the height of the fractured zone is the control height of the ninth strata $(68 \mathrm{~m})$.

Establishment of overburden fracture evolution model. Based on the on-site geological conditions, the overburden fracture evolution model of the mining face is established according to the calculation method of the key strata theory, the fracture angle of layer theory and the "three zones" theory, as shown in Fig. 5.

The blue line in the figure is the first roof breaking interval of the key stratum floor, which is made at the boundary according to the first fracture angle and the control height of the key stratum. The green line in the figure is the periodic roof breaking interval of the key stratum floor, which is made according to the connection between the periodic fracture angle and the control height of the key stratum. The overburden fracture evolution model shows that the overall whole fracture angle of overburden at the open-off cut side is basically the same as the rock fracture angle. The whole fracture angle of overburden at the mining side is greatly affected by the roof breaking interval, breaking position and fracture angle of the lower strata, and its value fluctuates greatly, with an average value less than the periodic fracture angle of the rock. The periodic fracture angle and roof breaking interval of the first key stratum of the coal seam roof are affected by the mining speed, while the periodic roof breaking interval of the upper key stratum is affected by the periodic roof breaking interval, the fracture angle and the position of the lower key stratum.

\section{Similarity material model experiment}

Model establishment. The similarity material model experiment is based on the two-dimensional test bed of the laboratory of China University of Mining and Technology (Beijing). The length, width and height of the test bed are $3000 \mathrm{~mm}, 250 \mathrm{~mm}$ and $2000 \mathrm{~mm}$ respectively. According to the similarity principle ${ }^{50}$, the geometric similarity ratio between the entity and the model is set as 200 , the time similarity ratio is set as 14.14 , the gravity similarity ratio is set as 1.6 , and the stress similarity ratio is set as 320 .

The displacement observation points and strain monitoring points were set in the experimental model. The similar materials were sand, lime, gypsum and water, and the model materials were proportioned according to the similarity ratio. The No. ratios of each layer are shown in Table 1. Mica slices were placed between adjacent layers to simulate stratification. The physical model was constructed layer by layer with a thickness of approximately $10 \mathrm{~mm}$ and a total thickness of $1.4 \mathrm{~m}$. The completed physical model was allowed to dry naturally. The physical model after removing the mold is shown in Fig. 6.

The range of the model simulates: $12.6 \mathrm{~m}$ below the coal floor, $480 \mathrm{~m}$ above the roof and a $5.4 \mathrm{~m}$ thick coal seam on average. The height of the simulated is approximately $498 \mathrm{~m}$, the height of the simulated material is 


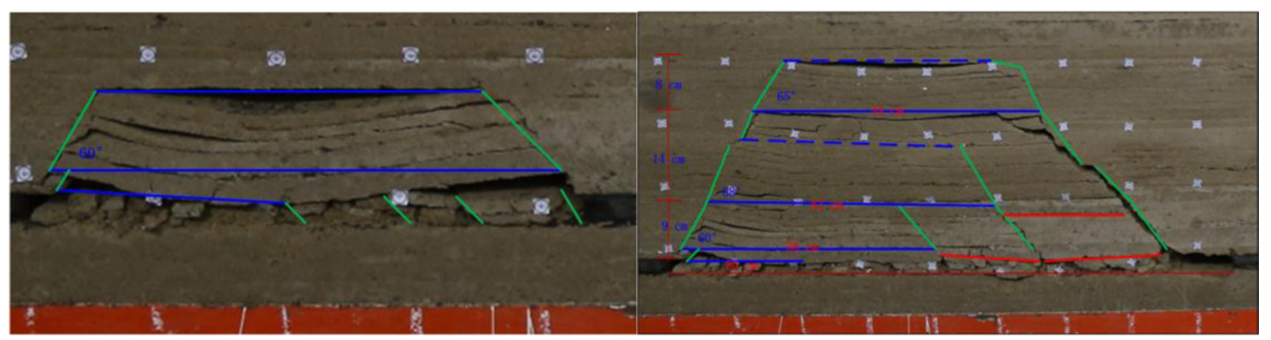

(a)

(b)

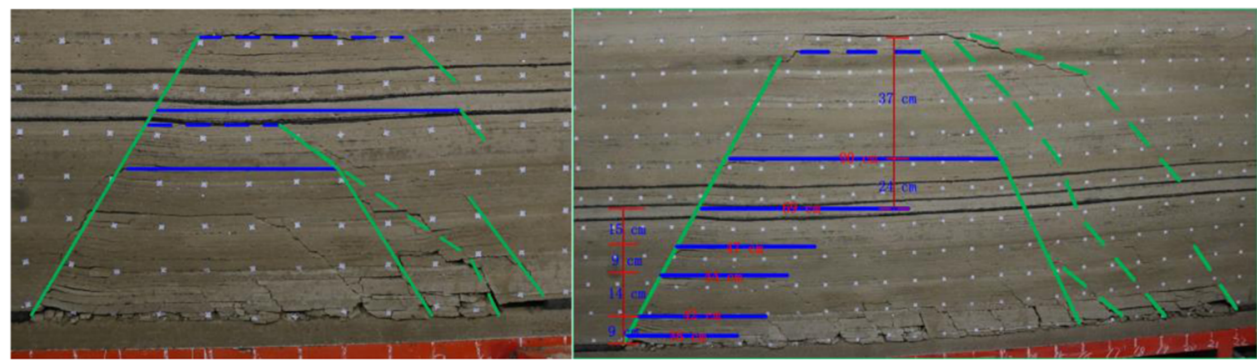

(c)

(d)

Figure 7. Overburden evolution process.

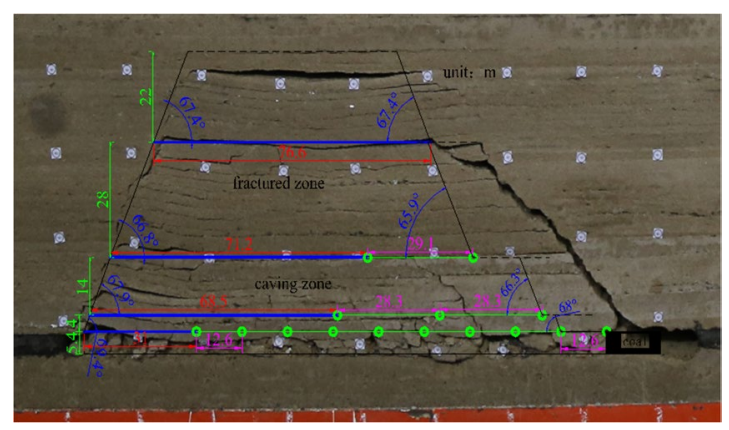

Figure 8. Comparison of experimental and theoretical models.

approximately $280 \mathrm{~m}$, and the remainder of the height is only simulated to the surface with a counterweight of approximately $218 \mathrm{~m}$.

Mining process. In the model, the displacement, strain, fracture angle, interval of roof collapse and height of roof collapse development were recorded for each mining $5 \mathrm{~cm}$. The model status at mining depths of $43 \mathrm{~cm}$, $85 \mathrm{~cm}, 115 \mathrm{~cm}$ and $220 \mathrm{~cm}$ is shown in Fig. $7(\mathrm{a}-\mathrm{d})$.

In Fig. 7(a-d), the blue horizontal line is the first interval of roofing breaking of the key stratum floor, and the interval is made at the boundary according to the first fracture angle and the control height of the key stratum. The red vertical line is the control height of the key stratum, the blue dotted line is the control height of the key stratum at the first breakage, and the green oblique line is the rock stratum fracture angle. A total of $220 \mathrm{~cm}$ is mined in a similar model, and there are 7 layers of fractures in the key overburden strata above the roof of the coal seam. The roof breaking interval are $20 \mathrm{~cm}, 38 \mathrm{~cm}, 42 \mathrm{~cm}, 44 \mathrm{~cm}, 47 \mathrm{~cm}, 69 \mathrm{~cm}$ and $90 \mathrm{~cm}$. The control heights of the fractures are $2 \mathrm{~cm}, 7 \mathrm{~cm}, 14 \mathrm{~cm}, 9 \mathrm{~cm}, 15 \mathrm{~cm}, 24 \mathrm{~cm}$ and $37 \mathrm{~cm}$.

When the model was mined $85 \mathrm{~cm}$, four key strata were broken. A comparison with the theoretical calculation model is shown in Fig. 8. The overall shapes of the theoretical calculation model and experimental model are basically the same. Due to the stratification complexity of the experimental model, the breakage position of the lower strata affects the upper strata, the fracture angle of the experimental model is slightly less than the theoretical calculated value, the control height of the key strata in the experimental model is basically consistent with the theoretical calculated value, and the roof breaking interval of the experimental model is slightly larger than the theoretically calculated value.

Collapse law of the model. The collapse length and height of the immediate and main roof were measured using millimeter steel rulers in the experiment. Figure 9 shows the length and height of overburden collapse during mining. 


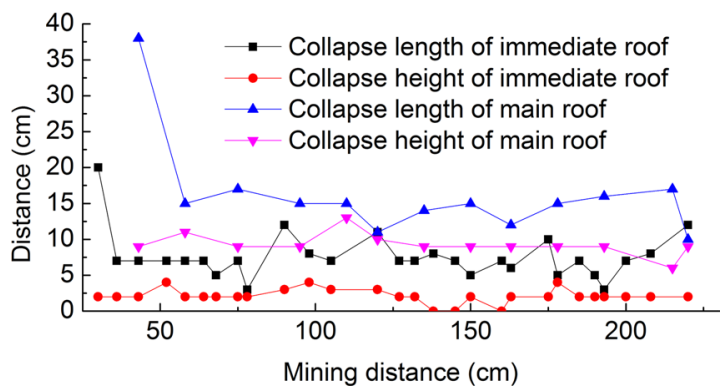

Figure 9. The relationship between the mining distance and collapse.

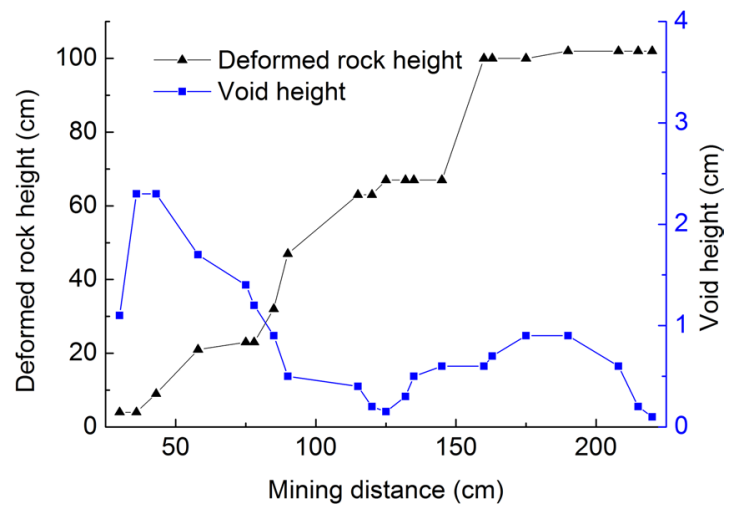

Figure 10. The relationship between the mining distance and deformed rock height and void height.

The average value of the collapse height of the immediate roof was $2.11 \mathrm{~cm}$, the first interval of roofing breaking was $20 \mathrm{~cm}$, and the periodic interval mean of roofing breaking was $7.11 \mathrm{~cm}$. The average collapse height of the main roof is $9.31 \mathrm{~cm}$, the first interval of roofing breaking is $38 \mathrm{~cm}$, and the average of the periodic interval of roofing breaking is $14.33 \mathrm{~cm}$. The collapse length of the main roof was roughly twice as long as that of the immediate roof. The height of the caving zone is basically $9 \mathrm{~cm}$ high, and the actual height is $18 \mathrm{~m}$ due to the model scale of 200 .

The maximum vertical distance between the strata with obvious movement and deformation during the process of mining and the roof of the coal seam is called the deformed rock height. The vertical distance between the highest strata with movement and the upper strata without movement is called the void height. During the mining process, the relation between the mining interval and deformed rock height and void height is shown in Fig. 10.

The mining interval is roughly twice the deformed rock height. Due to the synchronous deformation of the rock strata at a certain height controlled by the key strata, the deformed rock height will jump up after stabilizing for a certain interval during the mining process of the working face. With the mining of the working face, the void height gradually decreases after reaching the maximum value, and the amplitude gradually decreases and reaches the minimum value. The void height rises slightly after the goaf is re-compacted. It is speculated that the void height will change periodically with the deformed rock height, and the change side value is not large.

The ratio of the void height difference and the deformed rock height difference has a positive correlation with the dilatancy of the overburden. In addition, the ratio mentioned in the previous section and the ratio of the accumulated void height difference and the deformed rock height difference in the mining process were analyzed, as shown in Fig. 11.

When the mining interval is $85 \mathrm{~cm}$, the deformed rock height is $32 \mathrm{~cm}$; when the mining interval is $90 \mathrm{~cm}$, the deformed rock height is $47 \mathrm{~cm}$. The relationship between the deformed rock height and the ratio of the void height difference and deformed rock height difference was analyzed. When the deformed rock height is $32 \mathrm{~cm}$, the ratio is relatively large; when the deformed rock height reaches $47 \mathrm{~cm}$, the value decreases rapidly and then decreases slowly. It can be concluded that when the overburden is $32 \mathrm{~cm}$ high, the rock has a relatively large dilatancy, and its fractures are also developed. When the overburden is higher, the overburden has a relatively small dilatancy, and its fractures are not fully developed. It can be inferred that the upper limit of the fractured zone height is $32 \mathrm{~cm}$, and the actual height is $64 \mathrm{~m}$ due to the model scale of 200 . The dilatancy and fracture development of overlying strata are in direct proportion to the difference in the deformed rock height in the overlying strata, and the difference in the void height attenuates with mining, indicating that the dilatancy of the overlying strata decreases in the direction of the height. 


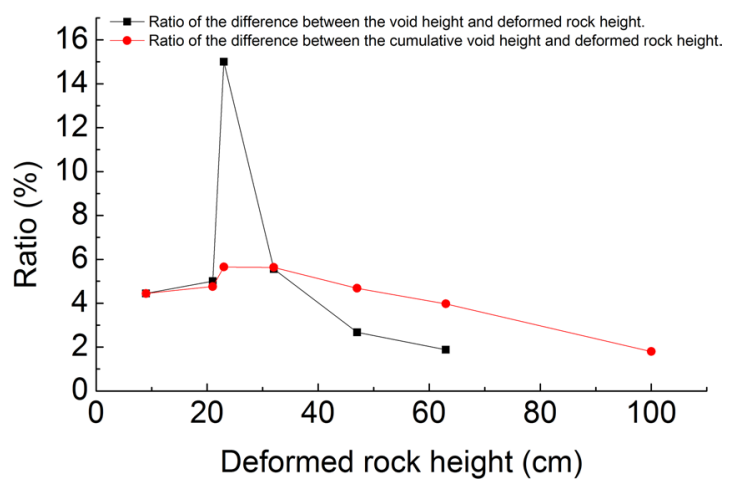

Figure 11. The relationship between the deformed rock height and ratio.

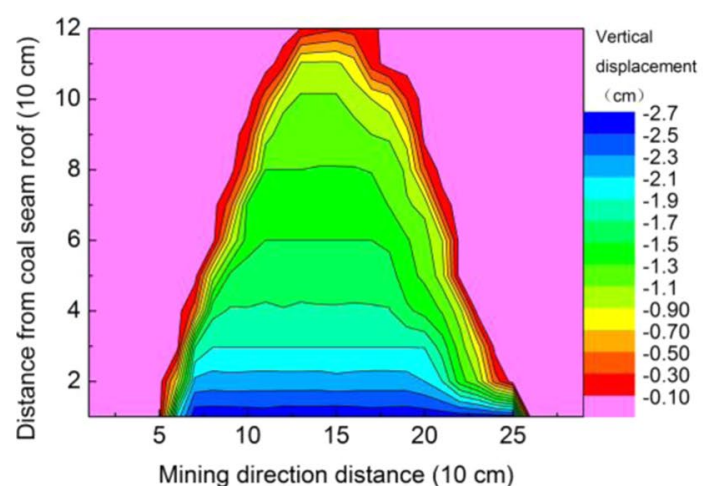

(a)

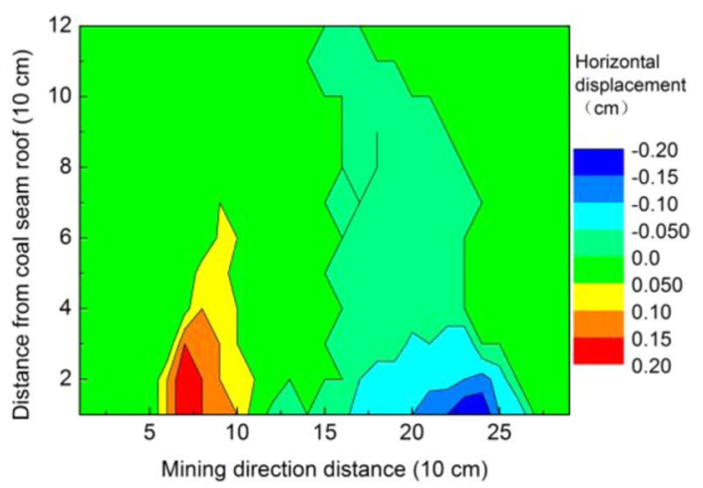

(b)

Figure 12. Distribution of the overburden displacement.

The displacement of overburden. In the model, displacement observation points begin to be arranged at a height of $1 \mathrm{~cm}$ above the coal seam, with a horizontal interval of $10 \mathrm{~cm}$. There are 29 displacement observation points in each layer, and the number of displacement observation points in the first layer is A01, A02, A03..., A29. One layer of displacement observation point is arranged $10 \mathrm{~cm}$ high at every interval, and 12 displacement observation points are published. The serial numbers are A, B, C.., L, and the displacement observation point has a $12 * 29$ grid shape.

After the model is dried, displacement observation points are arranged. To facilitate the recording and processing of displacement data, grids are arranged from bottom to top and from left to right (from line to column $(i, j))$. The Electronic Total Station was used to measure each displacement observation point successively before mining, and the displacement observation point was measured again when mining to $220 \mathrm{~cm}$. The vertical displacement and horizontal displacement distribution of the overburden were obtained by comparing the two displacement observation points, as shown in Fig. 12(a,b), respectively. The distribution of the overburden separation rate was obtained by calculating the displacement difference and the distance between two points. The ratio of the vertical displacement difference and the vertical distance between two points and the ratio of the horizontal displacement difference and the horizontal distance between two points are shown in Fig. 13(a,b), respectively.

In coal seam mining, the overburden strata mainly subsided, the horizontal displacement was very small, and the vertical displacement of the overlying strata all sank within the influence range. The closer to the coal seam, the greater the subsidence is and the larger the influence scope is, and the vertical displacement is attenuated when it develops toward the height. The vertical displacement change in the overlying strata on the side of the open-off cut is relatively uniform, and void development is stable. The vertical displacement change in the overlying strata on the mining side is uneven, and the development of voids is unstable.

During the process of coal seam mining, the horizontal displacement of the overlying strata tends to move toward the middle in the affected area; that is, the overlying strata on the side of the open-off cut move toward the mining direction, the overlying strata on the side of the mining move toward the open-off cut direction, and the upward part moves less. Horizontal displacement attenuates in the direction of height development, which indicates that the void and fracture in the overburden rock layer closer to the coal seam are more developed. The horizontal displacement at both ends of the open-off cut side and mining side is larger, which indicates that the void and fracture here are more developed.

The height of $10 \mathrm{~cm}$ with a vertical displacement greater than $2.3 \mathrm{~cm}$ and the height of $10 \mathrm{~cm}$ with a vertical separation rate greater than $4 \%$ can be judged as a caving zone with a height of $10 \mathrm{~cm}$. The height of $30 \mathrm{~cm}$ with a vertical displacement greater than $1.9 \mathrm{~cm}$ and the height of $30 \mathrm{~cm}$ with a vertical separation rate greater than $2 \%$ 


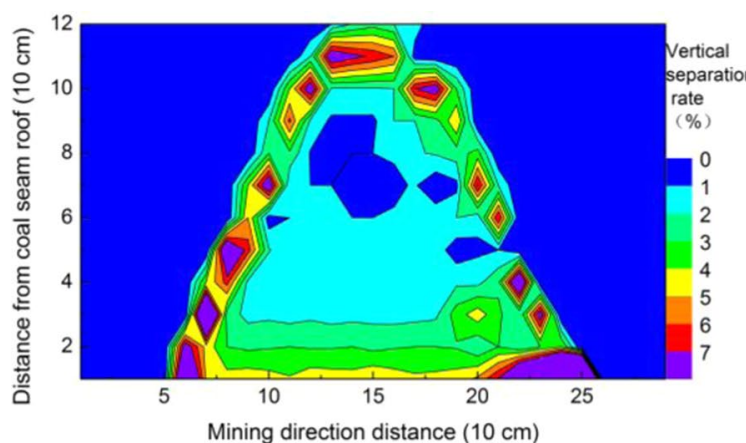

(a)

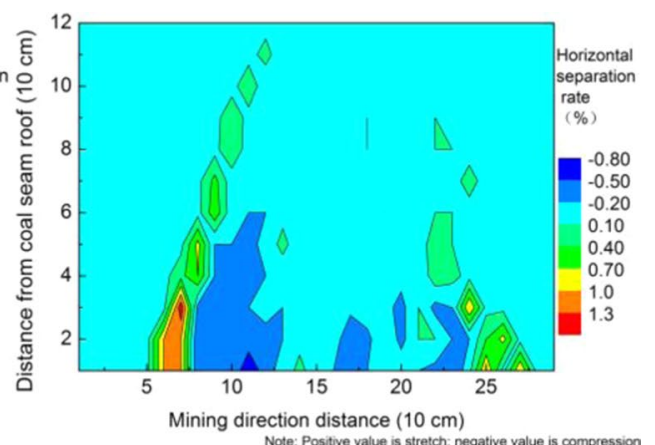

(b)

Figure 13. Distribution of the overburden separation rate.

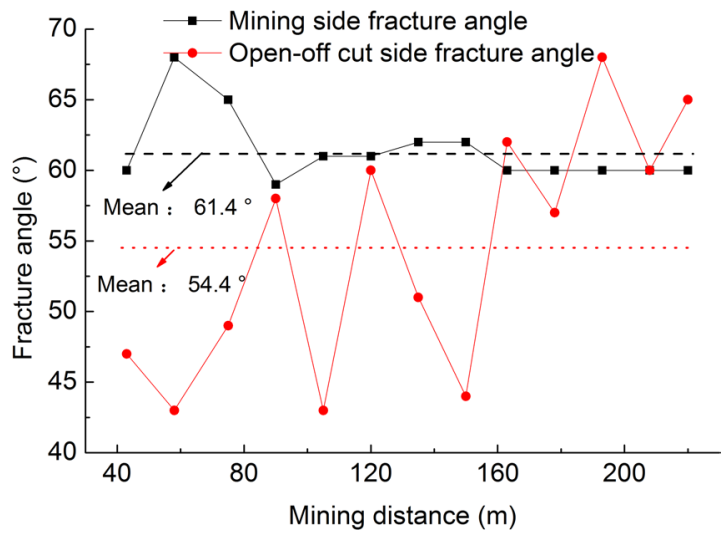

Figure 14. Relationship between the fracture angle and mining distance.

can be judged as a fractured zone with a height of $30 \mathrm{~cm}$. The comprehensive analysis shows that the width of the "O" ring is approximately $20 \mathrm{~cm}$.

The dilatancy and fracture development of the overlying strata are positively correlated with the displacement and separation rate of the overlying strata, and the displacement and separation rate decrease with the distance from the roof of the coal seam, indicating that the dilatancy and fracture of the overlying strata decrease in the height direction. The displacement and separation rate at both ends are relatively large, that is, the "O" ring, indicating that at the same level, the fractures at both ends of the open-off cut and mining side are more developed.

Overburden fracture angle. During the process of model mining, the fracture angles on both sides of the overburden were measured bya protractor every time the overburden collapsed. The whole fracture angles on the open-off cut side and the mining side are statistically analyzed when the miningare $43 \mathrm{~cm}, 58 \mathrm{~cm}, 75 \mathrm{~cm}, 90 \mathrm{~cm}$, $105 \mathrm{~cm}, 120 \mathrm{~cm}, 135 \mathrm{~cm}, 150 \mathrm{~cm}, 163 \mathrm{~cm}, 178 \mathrm{~cm}, 193 \mathrm{~cm}, 208 \mathrm{~cm}$ and $220 \mathrm{~cm}$. The results are shown in Fig. 14.

The whole fracture angle of the experimental model is consistent with the theoretical analysis. That is, the whole fracture angle of the overburden at the open-off cut side is basically consistent with the rock fracture angle, and the whole fracture angle of overburden at the mining side fluctuates greatly, whose mean is less than the rock periodic fracture angle.

During mining, the whole fracture angle at the open-off cut side fluctuates very little, with a mean of $61.4^{\circ}$. The whole fracture angle at the mining side fluctuates periodically with the mining of the working face, which is generally smaller than that at the open-off cut side and floats at a mean of $54.4^{\circ}$. The fracture at the side of the open-off cut develops steadily and upward, and the variation amplitude of fracture at the mining side is relatively large. The fracture on the mining side experienced the development and closure of the fracture during the process of upward development. On the whole, the development of the fracture at the side of mining is smaller than that on the side of the open-off cut.

Strain at monitoring point. In the model, a resistance strain gauge was arranged in the middle of $\mathrm{k} 2$ limestone at the total height of the model at $19 \mathrm{~cm}$ and a height of $10 \mathrm{~cm}$ of coal seam roof. The position $50 \mathrm{~cm}$ away from the model boundary was seen as the open-off cut. The first strain monitoring point was arranged at the position of $-10 \mathrm{~cm}$ on the side of the open-off cut, and a total of 10 strain observation points were arranged at a horizontal interval of $20 \mathrm{~cm}$. The 10th strain observation point was located $170 \mathrm{~cm}$ from the open-off cut. The 


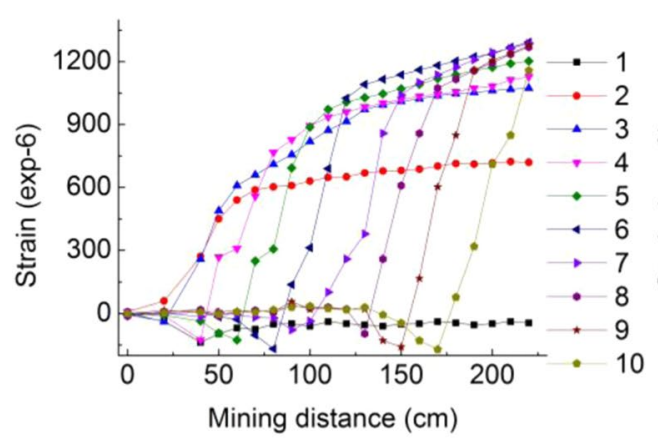

(a)

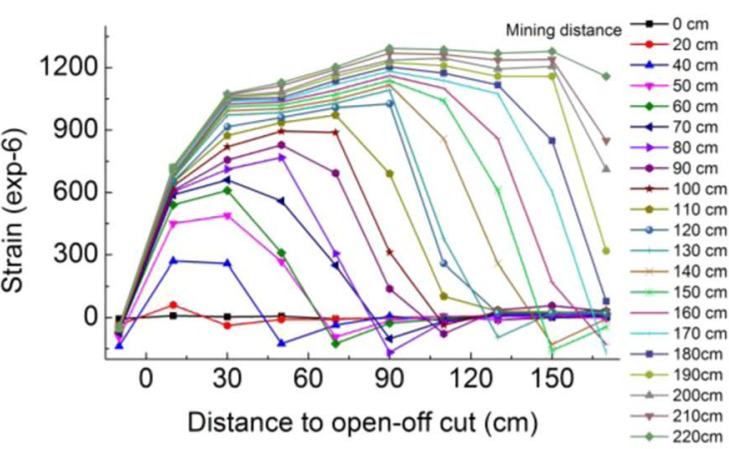

(b)

Figure 15. Relationship between the strain and mining distance.

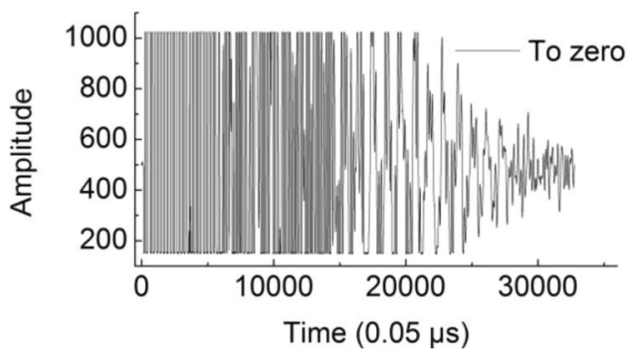

(a) To zero

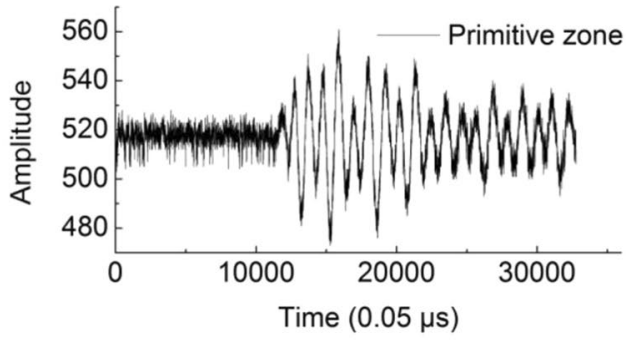

(b) Primitive zone

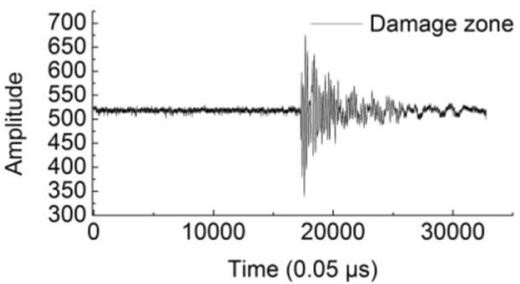

(c) Damage zone

Figure 16. The P-wave shape.

resistance strain gauge buried in the experimental model was connected to a laptop through a TCD-2A resistance strain collector, and the strain values were displayed on the laptop through supporting software.

Before mining, the value at each strain point was measured and recorded every $10 \mathrm{~cm}$ mined. The change in strain value at each single point with mining distance and strain distribution at each point at different mining distances are shown in Fig. 15(a,b), respectively.

The strain value of each strain monitoring point decreased slightly after mining, then increased rapidly, and finally tended to be stable. Due to the concentration of stress at both ends of the goaf during the process of mining, a small negative value of strain appeared, the stress inside the goaf was released suddenly, and the strain increased rapidly.

Overburden damage zone. The model was tested by the rock acoustic wave parameter tester HS-YS4A. The test adopted a voltage of $160 \mathrm{~V}$, a frequency of $100 \mathrm{~Hz}$, a single channel straight through, a sampling size of 32 $\mathrm{k}$, a sampling interval of $0.05 \mu \mathrm{s}$, an attenuation factor of 4 times, and a pulse width of $30 \mu \mathrm{s}$.

The length of the test model is $25 \mathrm{~cm}$, and the p-wave velocity is obtained from the measured time and distance. Figure 16(a-c) hows the p-wave waveform measured for zero, the primitive zone and the damage zone. The measured p-wave time is $2.6 \mu$ s for zero, $564.0 \mu$ s for the primitive zone and 867.8 us for the damage zone.

It can be analyzed from the measurement that the $\mathrm{p}$-wave velocity spreads the fastest in the primitive zone and the slowest in the damage zone, and the $\mathrm{p}$-wave amplitude and rate in the damage zone is obviously larger than those in the primitive zone. Therefore, the measurement of the $\mathrm{p}$-wave velocity can be used to detect fracture development in the model.

The variation in the $\mathrm{p}$-wave velocity before and after rock damage can characterize the damage value, and the calculation formula is as follows: 


$$
D=1-\left(\frac{v_{1}}{v_{0}}\right)^{2}
$$

Where $D$ represents the damage value of rock, $v_{0}$ represents the p-wave velocity of the primitive zone, $\mathrm{m} / \mathrm{s}$, and $v_{1}$ stands for the $\mathrm{p}$-wave velocity of rock after damage, $\mathrm{m} / \mathrm{s}$.

The damage value of the rock in the model is 0.568 .

\section{Conclusions}

The overburden fracture evolution model obtained by theoretical calculation is consistent with the overburden breaking law obtained by the model experiment, and the two "three zones" are basically the same height. The overburden fracture angle and roof breaking interval control the overburden collapse, and the obtained overburden separation rate distribution provides theoretical guidance for the horizon selection of high- and low-level gas drainage roadways.

1) The cylinder sample model is made with sand, lime, gypsum and water, and the equation of compressive strength and No. ratio are fitted through a test of the compressive strength, and the No. ratio of similar materials corresponding to the compressive strength can be obtained.

2) According to the control height of the key strata and "three zones" theoretical calculation results of the overburden, the height of caving zone is the control height of the second key strata, $18 \mathrm{~m}$, and the height of fractured zone is the control height of the ninth stratum, $68 \mathrm{~m}$. From the overburden fracture evolution model established based on the theoretical calculation, it can be concluded that the whole fracture angle of the overburden at the open-off cut side is basically consistent with the rock fracture angle, and the whole fracture angle of overburden at the mining side fluctuates greatly, whose mean is less than the rock periodic fracture angle.

3) The similarity model is established to obtain the key strata controlling the synchronous collapse of the upper strata, and the roof breaking interval of the upper key strata is larger than that of the lower key strata, with the similarity principle. The rock collapse in the caving zone is periodic, and the caving height is $9 \mathrm{~cm}$. According to the deformed rock height and the void height in the mining process, the upper limit of the height of the fractured zone is $32 \mathrm{~cm}$, and the mining interval is approximately twice the deformed rock height.

4) The distribution law of the overburden separation rate is obtained according to the overburden displacement, and the height of the caving zone is $10 \mathrm{~cm}$, the height of the fractured zone is $30 \mathrm{~cm}$, and the width of the "O" ring is $20 \mathrm{~cm}$. The whole fracture angle of the overburden in the experimental model is smaller than that of the rock strata. The whole fracture angle at the open-off side fluctuates very little with the advancement of the mining process, with a mean of $61.4^{\circ}$. The whole fracture angle on the mining side fluctuates at a mean of $54.4^{\circ}$ with the mining of the working face.

5) Due to the stress concentration at both ends of the goaf during the mining process, the strain appears to have a small negative value, the stress inside the goaf is suddenly released, and the strain increases rapidly. The p-wave velocity spreads quickly in the primitive zone and slowly in the damage zone, and the p-wave amplitude and rate in the damage zone is significantly larger than that in the primitive zone. Therefore, the p-wave velocity can be measured to detect the fracture development in the model, and the damage value of the rock in the model is 0.568 .

\section{Data availability}

The primary data used to support the findings of this study are available from the corresponding author upon request.

Received: 16 December 2019; Accepted: 1 April 2020;

Published online: 16 April 2020

\section{References}

1. Liu, S. et al. Mechanical and acoustic emission characteristics of coal at temperature impact. Natural Resources Research, https://doi. org/10.1007/s11053-019-09562-w (2019).

2. Liu, S., Wang, D., Yin, G., Li, M. \& Li, X. Experimental Study on the Microstructure Evolution Laws in Coal Seam Affected by Temperature Impact. Rock Mech Rock Eng, https://doi.org/10.1007/s00603-019-01978-3 (2019).

3. Madhavi, M. \& Nuttall, W. J. Coal in the twenty-first century: a climate of change and uncertainty. Proceedings of the Institution of Civil Engineers - Energy 172, 46-63, https://doi.org/10.1680/jener.18.00011 (2019).

4. Karacan, C. Ö., Esterhuizen, G. S., Schatzel, S. J. \& Diamond, W. P. Reservoir simulation-based modeling for characterizing longwall methane emissions and gob gas venthole production. International Journal of Coal Geology 71, 225-245, https://doi.org/10.1016/j. coal.2006.08.003 (2007).

5. Palchik, V. Formation of fractured zones in overburden due to longwall mining. Environmental Geology 44, 28-38, https://doi. org/10.1007/s00254-002-0732-7 (2003).

6. Qu, Q., Xu, J., Wu, R., Qin, W. \& Hu, G. Three-zone characterisation of coupled strata and gas behaviour in multi-seam mining. Int J Rock Mech Min 78, 91-98, https://doi.org/10.1016/j.ijrmms.2015.04.018 (2015).

7. Singh, M. M. \& Kendorski, F. S. Strata disturbance prediction for mining beneath surface water and waste impoundments. International Journal of Rock Mechanics and Mining Sciences \& Geomechanics Abstracts 20, A13, https://doi.org/10.1016/01489062(83)91724-2 (1983).

8. Dou, L., He, X., He, H., He, J. \& Fan, J. Spatial structure evolution of overlying strata and inducing mechanism of rockburst in coal mine. Transactions of Nonferrous Metals Society of China 24, 1255-1261, https://doi.org/10.1016/s1003-6326(14)63187-3 (2014). 
9. Suchowerska, A. M., Carter, J. P. \& Merifield, R. S. Horizontal stress under supercritical longwall panels. Int J Rock Mech Min 70, 240-251, https://doi.org/10.1016/j.ijrmms.2014.03.009 (2014).

10. Wang, H., Zhang, D., Wang, X. \& Zhang, W. Visual Exploration of the Spatiotemporal Evolution Law of Overburden Failure and Mining-Induced Fractures: A Case Study of the Wangjialing Coal Mine in China. Minerals 7, 35, https://doi.org/10.3390/ $\min 7030035(2017)$.

11. Wen, J., Cheng, W., Chen, L., Shi, S. \& Wen, Z. A study of the dynamic movement rule of overlying strata combinations using a short-wall continuous mining and full-caving method. Energy Science \& Engineering, https://doi.org/10.1002/ese3.474 (2019).

12. Zhou, Y., Li, M., Xu, X. \& Li, M. A study on dual-load-zone model of overlying strata and evolution law of mining stress. Computers, Materials \& Continua 58, 391-407, https://doi.org/10.32604/cmc.2019.04456 (2019).

13. Han, Y. et al. Prediction of the height of overburden fractured zone in deep coal mining: case study. Archives of Mining Sciences 63, 617-631, https://doi.org/10.24425/123687 (2018).

14. He, H., Dou, L., Cao, A. \& Fan, J. Mechanisms of mining seismicity under large scale exploitation with multikey strata. Shock Vib 2015, 1-9, https://doi.org/10.1155/2015/313069 (2015).

15. Sun, Y., Zuo, J., Karakus, M. \& Wang, J. Investigation of movement and damage of integral overburden during shallow coal seam mining. Int J Rock Mech Min 117, 63-75, https://doi.org/10.1016/j.ijrmms.2019.03.019 (2019).

16. Fan, L. \& Liu, S. A conceptual model to characterize and model compaction behavior and permeability evolution of broken rock mass in coal mine gobs. International Journal of Coal Geology 172, 60-70, https://doi.org/10.1016/j.coal.2017.01.017 (2017).

17. Luan, H., Wang, J., Ma, G. \& Zhang, K. A practical nonprobabilistic reliability assessment method on key strata shear failure in longwall mining. Mathematical Problems in Engineering 2015, 1-8, https://doi.org/10.1155/2015/893019 (2015).

18. Liang, Y., Li, B. \& Zou, Q. Movement type of the first subordinate key stratum and its influence on strata behavior in the fully mechanized face with large mining height. Arabian Journal of Geosciences 12, https://doi.org/10.1007/s12517-018-4208-9 (2019).

19. Xie, J. \& Xu, J. Effect of key stratum on the mining abutment pressure of a coal seam. Geosciences Journal 21, 267-276, https://doi. org/10.1007/s12303-016-0044-7 (2017).

20. Han, H., Xu, J., Wang, X., Xie, J. \& Xing, Y. Method to calculate working surface abutment pressure based on key strata theory. Adv Civ Eng 2019, 1-20, https://doi.org/10.1155/2019/7678327 (2019).

21. Gao, Y., Gao, F. \& Yeung, M. R. Modeling large displacement of rock block and a work face excavation of a coal mine based on discontinuous deformation analysis and finite deformation theory. Tunnelling and Underground Space Technology 92, 103048, https://doi.org/10.1016/j.tust.2019.103048 (2019).

22. Adhikary, D. P. \& Guo, H. Modelling of Longwall Mining-Induced Strata Permeability Change. Rock Mech Rock Eng 48, 345-359, https://doi.org/10.1007/s00603-014-0551-7 (2014).

23. Cheng, G., Ma, T., Tang, C., Liu, H. \& Wang, S. A zoning model for coal mining - induced strata movement based on microseismic monitoring. Int J Rock Mech Min 94, 123-138, https://doi.org/10.1016/j.ijrmms.2017.03.001 (2017).

24. Ghabraie, B., Ren, G., Smith, J. \& Holden, L. Application of 3D laser scanner, optical transducers and digital image processing techniques in physical modelling of mining-related strata movement. Int J Rock Mech Min 80, 219-230, https://doi.org/10.1016/j. ijrmms.2015.09.025 (2015).

25. Yang, D., Guo, W. \& Tan, Y. Study on the evolution characteristics of two-zone failure mode of the overburden strata under shallow buried thick seam mining. Adv Civ Eng 2019, 1-9, https://doi.org/10.1155/2019/9874769 (2019).

26. Yu, B., Zhao, J., Kuang, T. \& Meng, X. In situ investigations into overburden failures of a super-thick coal seam for longwall top coal caving. Int J Rock Mech Min 78, 155-162, https://doi.org/10.1016/j.ijrmms.2015.05.009 (2015).

27. Li, J. et al. The influences of key strata compound breakage on the overlying strata movement and strata pressure behavior in fully mechanized caving mining of shallow and extremely thick seams: a case study. Adv Civ Eng 2019, 1-11, https://doi. org/10.1155/2019/5929635 (2019)

28. Kang, H., Lou, J., Gao, F., Yang, J. \& Li, J. A physical and numerical investigation of sudden massive roof collapseduring longwall coal retreat mining. International Journal of Coal Geology 188, 25-36, https://doi.org/10.1016/j.coal.2018.01.013 (2018).

29. Le, T. D., Oh, J., Hebblewhite, B., Zhang, C. \& Mitra, R. A discontinuum modelling approach for investigation of Longwall Top Coal Caving mechanisms. Int J Rock Mech Min 106, 84-95, https://doi.org/10.1016/j.ijrmms.2018.04.025 (2018).

30. Wang, C., Zhang, N., Han, Y., Xiong, Z. \& Qian, D. Experiment research on overburden mining-induced fracture evolution and its fractal characteristics in ascending mining. Arabian Journal of Geosciences 8, 13-21, https://doi.org/10.1007/s12517-013-1178-9 (2013).

31. Pan, W., Nie, X. \& Li, X. Effect of premining on hard roof distress behavior: a case study. Rock Mech Rock Eng 52, 1871-1885, https:// doi.org/10.1007/s00603-018-1657-0 (2019).

32. Wang, G., Wu, M., Wang, R., Xu, H. \& Song, X. Height of the mining-induced fractured zone above a coal face. Engineering Geology 216, 140-152, https://doi.org/10.1016/j.enggeo.2016.11.024 (2017).

33. He, C., Xu, J., Wang, F. \& Wang, F. Movement boundary shape of overburden strata and Its influencing factors. Energies 11, 742, https://doi.org/10.3390/en11040742 (2018).

34. Yang, W. \& Xia, X. Study on mining failure law of the weak and weathered composite roof in a thin bedrock working face. J Geophys Eng 15, 2370-2377, https://doi.org/10.1088/1742-2140/aacedf (2018).

35. Ju, J. \& Xu, J. Structural characteristics of key strata and strata behaviour of a fully mechanized longwall face with $7.0 \mathrm{~m}$ height chocks. Int J Rock Mech Min 58, 46-54, https://doi.org/10.1016/j.ijrmms.2012.09.006 (2013).

36. Zhou, D. et al. Formation and development mechanism of ground crack caused by coal mining: effects of overlying key strata. Bulletin of Engineering Geology and the Environment 78, 1025-1044, https://doi.org/10.1007/s10064-017-1108-2 (2019).

37. Chai, J. \& Du, W. Experimental study on the application of BOTDA in the overlying strata deformation monitoring induced by coal mining. Journal of Sensors 2019, 1-9, https://doi.org/10.1155/2019/3439723 (2019).

38. Yan, H., Zhang, J., Zhang, S. \& Zhou, N. Physical modeling of the controlled shaft deformation law during the solid backfill mining of ultra-close coal seams. Bulletin of Engineering Geology and the Environment 78, 3741-3754, https://doi.org/10.1007/s10064-0181335-1 (2019).

39. Zhang, S., Fan, G., Zhang, D. \& Li, Q. Physical simulation research on evolution laws of clay aquifuge stability during slice mining. Environmental Earth Sciences 77, https://doi.org/10.1007/s12665-018-7401-y (2018)

40. Ghabraie, B., Ren, G. \& Smith, J. V. Characterising the multi-seam subsidence due to varying mining configuration, insights from physical modelling. Int J Rock Mech Min 93, 269-279, https://doi.org/10.1016/j.ijrmms.2017.02.001 (2017).

41. Yavuz, H. An estimation method for cover pressure re-establishment distance and pressure distribution in the goaf of longwall coal mines. Int J Rock Mech Min 41, 193-205, https://doi.org/10.1016/S1365-1609(03)00082-0 (2004).

42. Zhang, K., Yang, T., Bai, H. \& Pathegama Gamage, R. Longwall mining-induced damage and fractures: field measurements and simulation using FDM and DEM coupled method. International Journal of Geomechanics 18, 04017127, https://doi.org/10.1061/ (asce)gm.1943-5622.0001040 (2018)

43. Wu, Q., Shen, J., Liu, W. \& Wang, Y. A RBFNN-based method for the prediction of the developed height of a water-conductive fractured zone for fully mechanized mining with sublevel caving. Arabian Journal of Geosciences 10, https://doi.org/10.1007/ s12517-017-2959-3 (2017).

44. Chen, L., Fan, S., Zhao, C., Zhang, L. \& Cheng, Z. Calculation method of overburden damage height based on fracture mechanics analysis of soft and hard rock layers. Geofluids 2019, 1-15, https://doi.org/10.1155/2019/3790264 (2019). 
45. Qian, M., Shi, P. \& Xu, J. L. Mine pressure and rock formation control. 32-179 (China University of Mining and Technology Press (2010).

46. Miao, X., Cui, X., Wang, J. A. \& Xu, J. The height of fractured water-conducting zone in undermined rock strata. Engineering Geology 120, 32-39, https://doi.org/10.1016/j.enggeo.2011.03.009 (2011).

47. Zhang, H., Zhu, Z., Huo, L., Chen, Y. \& Huo, B. Overburden failure height of superhigh seam by fully mechanized caving method. Journal of China Coal Society 39, 816-821, https://doi.org/10.13225/j.cnki.jccs.2013.0641 (2014).

48. Singh, A., Rao, K. S. \& Ayothiraman, R. Study on Mohr-Coulomb-based three-dimensional strength criteria and its application in the stability analysis of vertical borehole. Arabian Journal of Geosciences 12, https://doi.org/10.1007/s12517-019-4752-y (2019).

49. Sun, D. A., Yao, Y.-P. \& Matsuoka, H. Modification of critical state models by Mohr-Coulomb criterion. Mechanics Research Communications 33, 217-232, https://doi.org/10.1016/j.mechrescom.2005.05.006 (2006).

50. Li, H. Similar simulation test of mine pressure. 3-24(China University of Mining and Technology Press (1988).

\section{Acknowledgements}

This study was funded by the National Key R\&D Program of China (Grant No. 2016YFC0801800), the National Natural Science Foundation of China (Grant No. 51704299 and Grant No. 51804311) and the Open Research Fund of State Key Laboratory of Coal Mine Safety Technology (Project No. sklcmst102).

\section{Author contributions}

H.Z., S.F. and Y.H. conceived and designed the study. All authors participated in the experimental process. H.Z., S.F., Y.H. and J.G. were involved in the data analysis. S.F., J.G., Y.W. and L.H. wrote the first draft of the manuscript. All authors have read and approved the final manuscript.

\section{Competing interests}

The authors declare no competing interests.

\section{Additional information}

Correspondence and requests for materials should be addressed to S.F.

Reprints and permissions information is available at www.nature.com/reprints.

Publisher's note Springer Nature remains neutral with regard to jurisdictional claims in published maps and institutional affiliations.

(c) (i) Open Access This article is licensed under a Creative Commons Attribution 4.0 International License, which permits use, sharing, adaptation, distribution and reproduction in any medium or format, as long as you give appropriate credit to the original author(s) and the source, provide a link to the Creative Commons license, and indicate if changes were made. The images or other third party material in this article are included in the article's Creative Commons license, unless indicated otherwise in a credit line to the material. If material is not included in the article's Creative Commons license and your intended use is not permitted by statutory regulation or exceeds the permitted use, you will need to obtain permission directly from the copyright holder. To view a copy of this license, visit http://creativecommons.org/licenses/by/4.0/.

(C) The Author(s) 2020 